Supporting Information

\title{
Engineering Nanoscale Interfaces of Metal/Oxide Nanowires to Control Catalytic Activity
}

Hee Chan Song, ${ }^{\dagger, \ddagger, \S}$ Gyu Rac Lee, ${ }^{\prime \prime, \S}$ Kiung Jeon, "Hyunhwa Lee, ${ }^{\dagger, \ddagger}$ Si Woo Lee, ${ }^{\dagger, \ddagger}$ Yeon Sik Jung, *, and Jeong Young Park, ,t,

${ }^{\dagger}$ Department of Chemistry, KAIST, Daejeon 34141, Republic of Korea

${ }^{*}$ Center for Nanomaterials and Chemical Reactions, Institute for Basic Science, Daejeon 34141, Republic of Korea

"Department of Materials Science and Engineering, KAIST, Daejeon 34141, Republic of Korea

${ }^{\S}$ H. C. Song and G. R. Lee contributed to this work equally.

*To whom correspondence should be addressed. E-mail: ysjung@kaist.ac.kr, jeongypark@kaist.ac.kr 


\section{Contents}

\section{Supporting Figures}

Figure S1. SEM image and non-contact AFM topography with the corresponding height profile of $\mathrm{Pt}$ and $\left(\mathrm{Pt} / \mathrm{TiO}_{2}\right)_{1} \mathrm{NWs}$

Figure S2. XPS spectra of $\mathrm{Pt} 4 \mathrm{f}$ for the $\mathrm{Pt} \mathrm{NW}, \mathrm{Pt} / \mathrm{TiO}_{2} \mathrm{NW}$, and $\mathrm{Pt} / \mathrm{CoO} \mathrm{NW}$ complexes

Figure S3. XPS spectra of Co $2 p$ for the $\mathrm{Pt} / \mathrm{CoO} \mathrm{NWs}$ before and after $\mathrm{CO}$ oxidation

Figure S4. XPS spectra of Ti $2 p$ for the $\mathrm{Pt} / \mathrm{TiO}_{2} \mathrm{NWs}$ before and after $\mathrm{CO}$ oxidation

Figure S5. XRD patterns for the $\mathrm{Pt} / \mathrm{CoO} \mathrm{NWs}$ before and after $\mathrm{CO}$ oxidation

Figure S6. XRD patterns for the $\mathrm{Pt} / \mathrm{TiO}_{2} \mathrm{NWs}$ before and after $\mathrm{CO}$ oxidation

Figure S7. SEM images for the NW complexes after $\mathrm{CO}$ oxidation reaction

Figure S8. The Arrhenius plots for the first and second cycle of $\left(\mathrm{Pt} / \mathrm{TiO}_{2}\right)_{1} \mathrm{NW}$ and $(\mathrm{Pt} / \mathrm{CoO})_{1} \mathrm{NW}$

Figure S9. Turnover number at $513 \mathrm{~K}$ as a function of reaction time for the first and second cycle of $\left(\mathrm{Pt} / \mathrm{TiO}_{2}\right)_{1} \mathrm{NW}$ and $(\mathrm{Pt} / \mathrm{CoO})_{1} \mathrm{NW}$

Figure S10. The kinetic study for the Pt NW, $\left(\mathrm{Pt} / \mathrm{TiO}_{2}\right)_{1},(\mathrm{Pt} / \mathrm{CoO})_{1}$, and $(\mathrm{Pt} / \mathrm{CoO})_{2} \mathrm{NW}$ complexes under 10 Torr $\mathrm{O}_{2}$ at $513 \mathrm{~K}$

Figure S11. SEM image of the $(\mathrm{Pt} / \mathrm{CoO})_{2} \mathrm{NWs}$

Figure S12. Interfacial products for the $\mathrm{Pt} / \mathrm{TiO}_{2}$ and $\mathrm{Pt} / \mathrm{CoO} \mathrm{NW}$ complexes at $513 \mathrm{~K}$ 

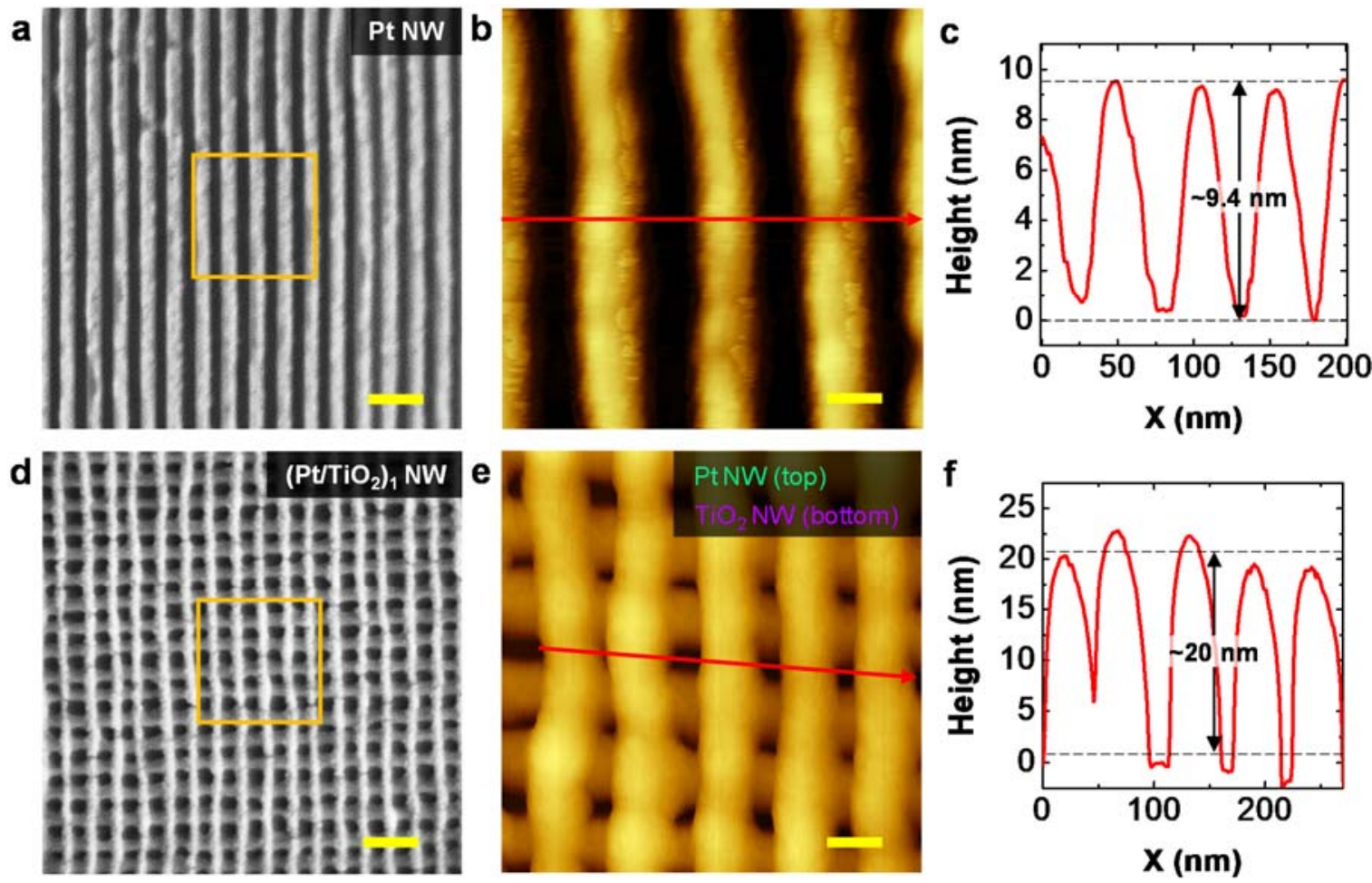

Figure S1. SEM image and non-contact AFM topography (orange square) with the corresponding height profile (red arrow) of as-prepared $(\mathrm{a}, \mathrm{b}, \mathrm{c}) \mathrm{Pt}$ nanowire and $(\mathrm{d}, \mathrm{e}, \mathrm{f})\left(\mathrm{Pt} / \mathrm{TiO}_{2}\right)_{1}$ nanowires. Scale bars in SEM and AFM images are $100 \mathrm{~nm}$ and $25 \mathrm{~nm}$, respectively. 

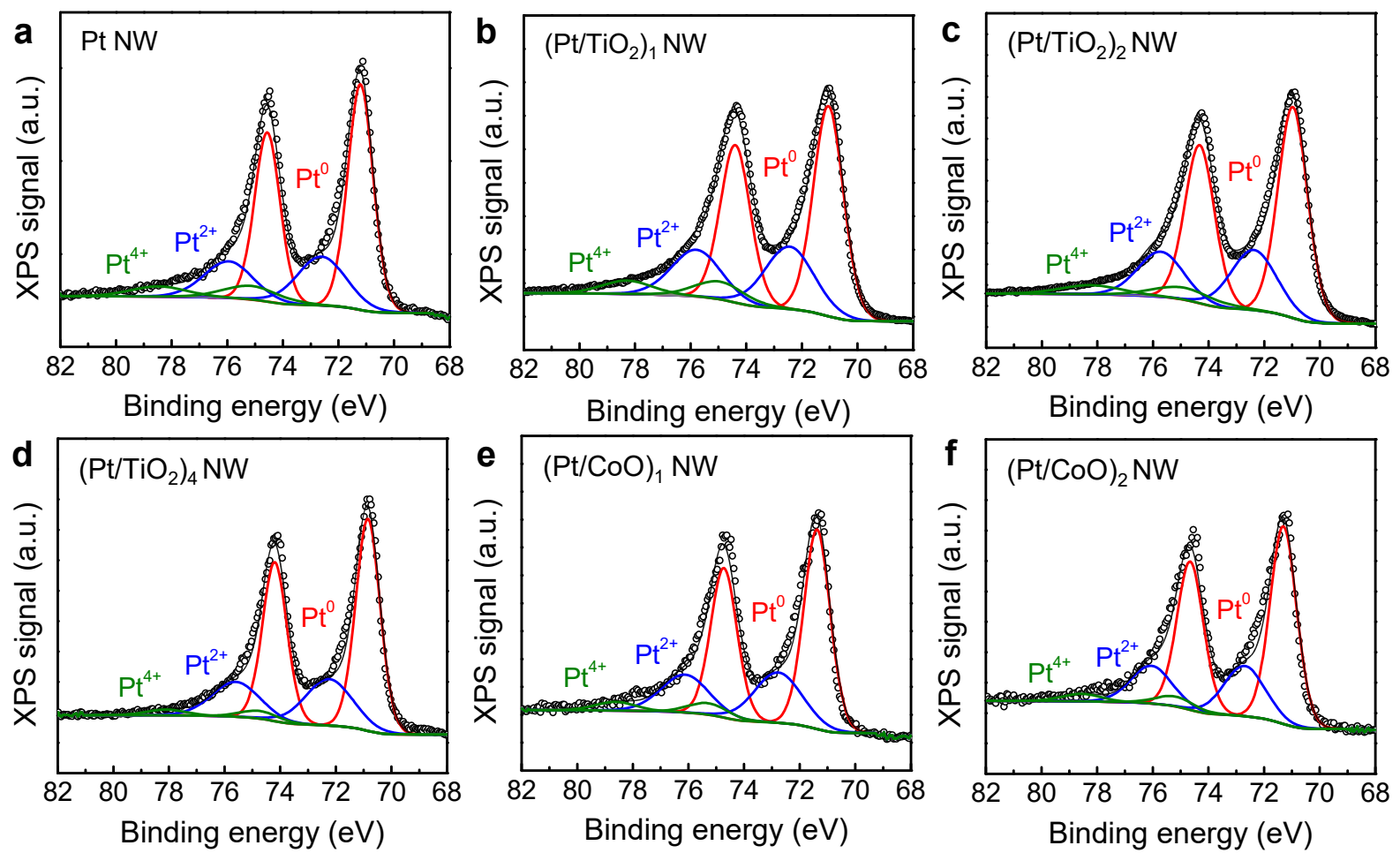

Figure S2. XPS spectra of $\mathrm{Pt} 4 \mathrm{f}$ for the (a) $\mathrm{Pt} \mathrm{NW}$ and (b) $\left(\mathrm{Pt} / \mathrm{TiO}_{2}\right)_{1}$, (c) $\left(\mathrm{Pt} / \mathrm{TiO}_{2}\right)_{2}$, (d) $\left(\mathrm{Pt} / \mathrm{TiO}_{2}\right)_{4}$, (e) $(\mathrm{Pt} / \mathrm{CoO})_{1}$, and (f) $(\mathrm{Pt} / \mathrm{CoO})_{2} \mathrm{NW}$ complexes. 

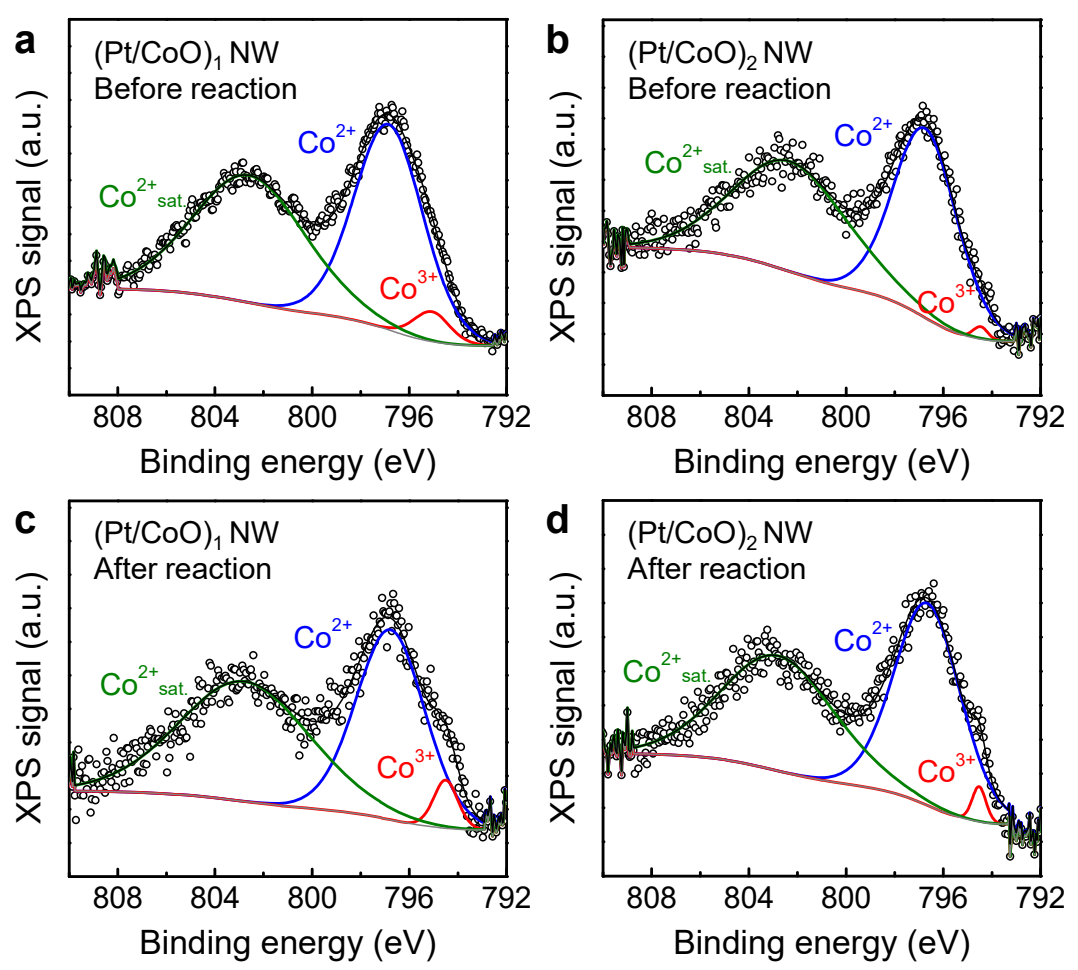

Figure S3. XPS spectra of $\mathrm{Co} 2 \mathrm{p}$ for the $(\mathrm{a}, \mathrm{c})(\mathrm{Pt} / \mathrm{CoO})_{1}$ and $(\mathrm{b}, \mathrm{d})(\mathrm{Pt} / \mathrm{CoO})_{2}$ nanowires before and after $\mathrm{CO}$ oxidation. 

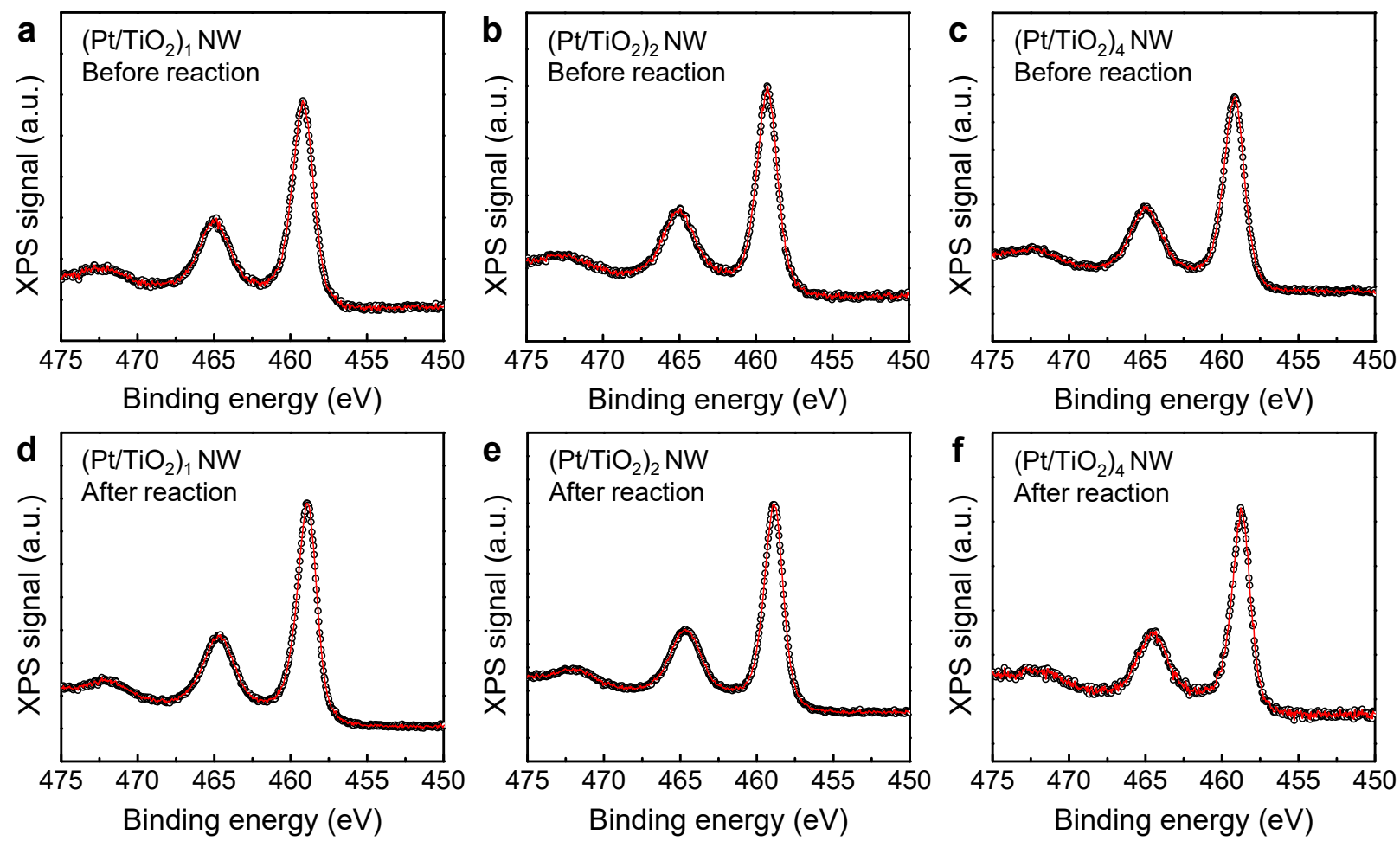

Figure S4. XPS spectra of Ti $2 \mathrm{p}$ for the $(\mathrm{a}, \mathrm{d})\left(\mathrm{Pt} / \mathrm{TiO}_{2}\right)_{1},(\mathrm{~b}, \mathrm{e})\left(\mathrm{Pt} / \mathrm{TiO}_{2}\right)_{2}$, and $(\mathrm{c}, \mathrm{f})\left(\mathrm{Pt} / \mathrm{TiO}_{2}\right)_{4}$ nanowires before and after $\mathrm{CO}$ oxidation. 

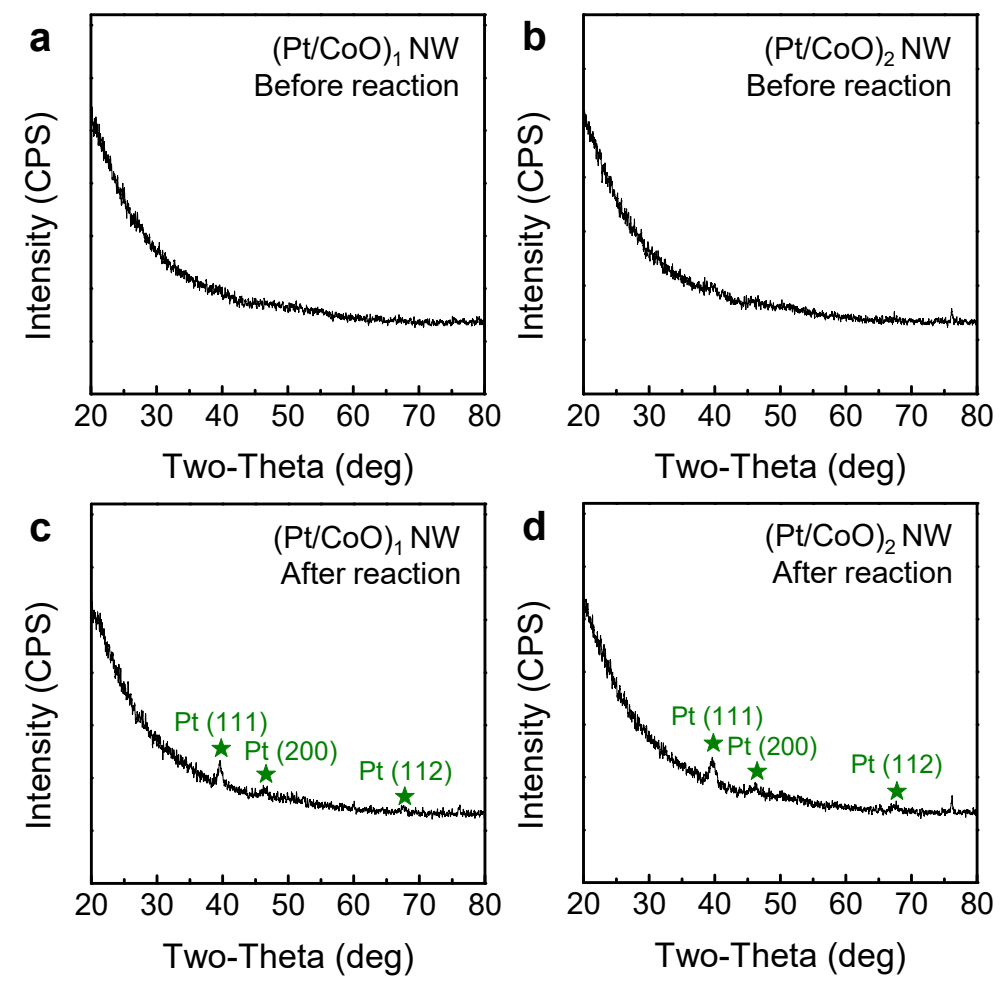

Figure S5. XRD patterns for the $(\mathrm{a}, \mathrm{c})(\mathrm{Pt} / \mathrm{CoO})_{1}$ and $(\mathrm{b}, \mathrm{d})(\mathrm{Pt} / \mathrm{CoO})_{2}$ nanowires before and after CO oxidation. 

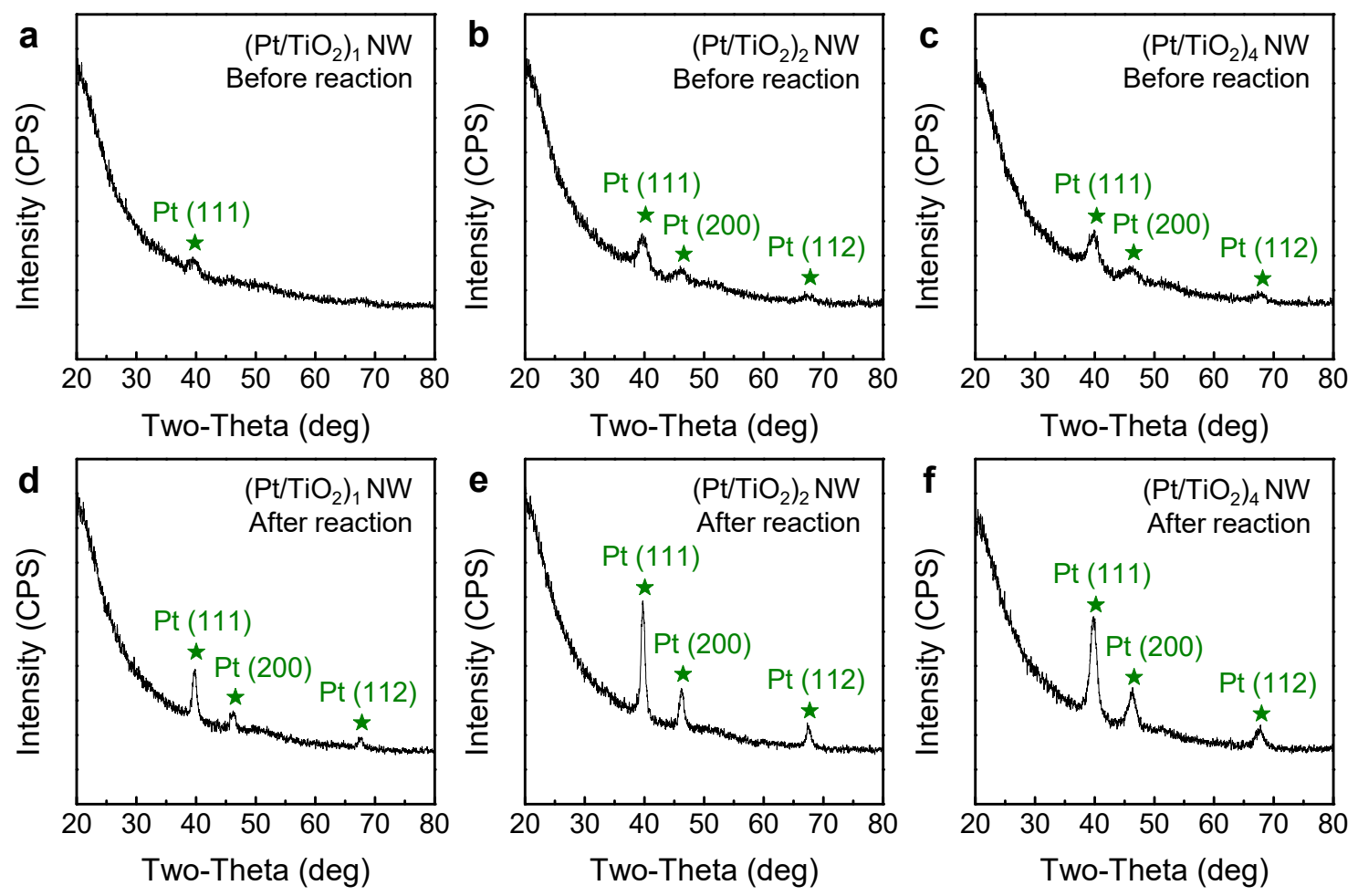

Figure S6. XRD patterns for the (a, d) $\left(\mathrm{Pt} / \mathrm{TiO}_{2}\right)_{1}$, (b, e) $\left(\mathrm{Pt} / \mathrm{TiO}_{2}\right)_{2}$, and $(\mathrm{c}, \mathrm{f})\left(\mathrm{Pt} / \mathrm{TiO}_{2}\right)_{4}$ nanowires before and after $\mathrm{CO}$ oxidation. 

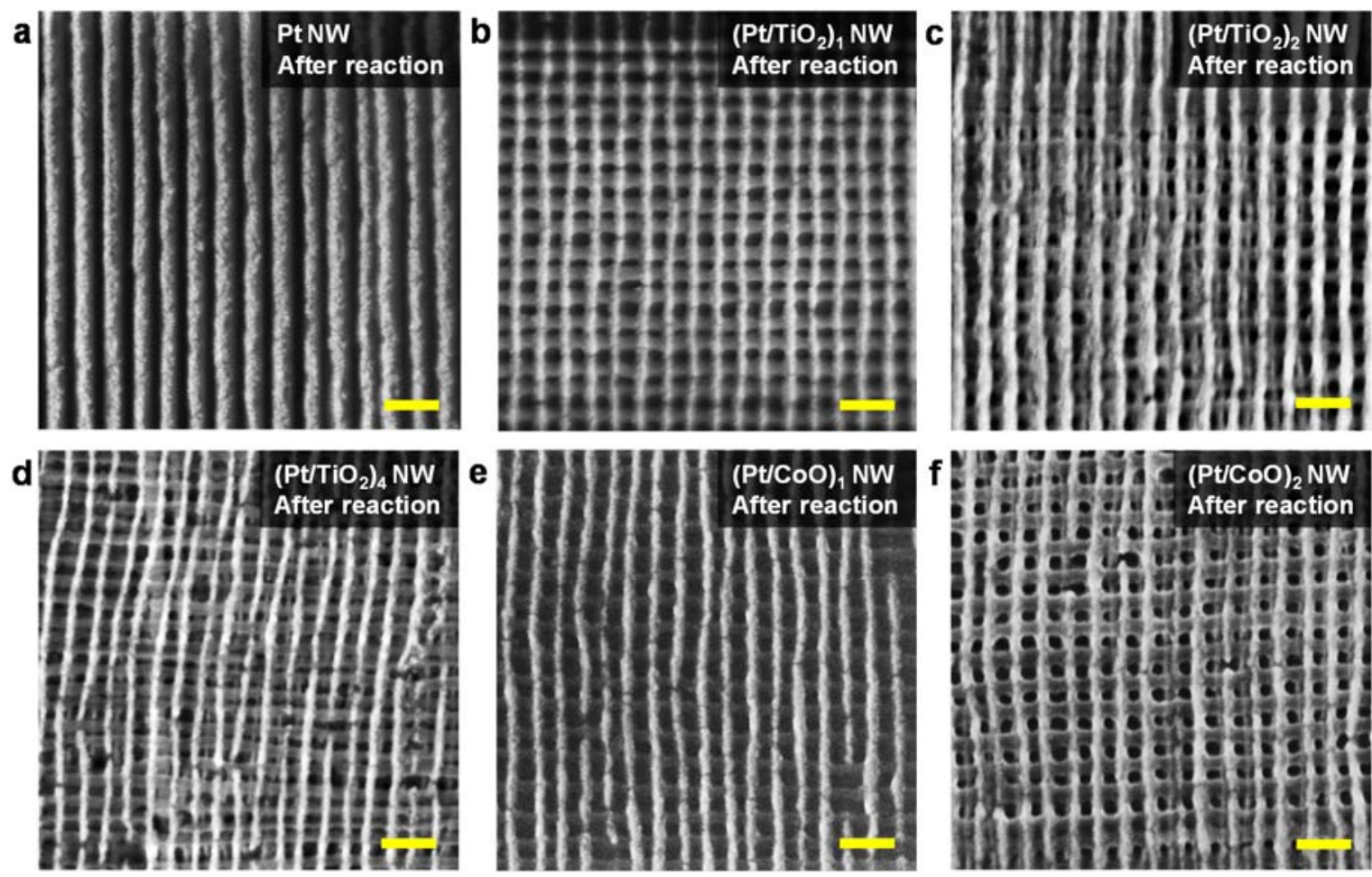

Figure S7. SEM images for the (a) Pt NW and (b) $\left(\mathrm{Pt} / \mathrm{TiO}_{2}\right)_{1}$, (c) $\left(\mathrm{Pt} / \mathrm{TiO}_{2}\right)_{2}$, (d) $\left(\mathrm{Pt} / \mathrm{TiO}_{2}\right)_{4}$, (e) $(\mathrm{Pt} / \mathrm{CoO})_{1}$, and $(\mathrm{f})(\mathrm{Pt} / \mathrm{CoO})_{2} \mathrm{NW}$ complexes after $\mathrm{CO}$ oxidation reaction. Scale bars in SEM images are $100 \mathrm{~nm}$. 

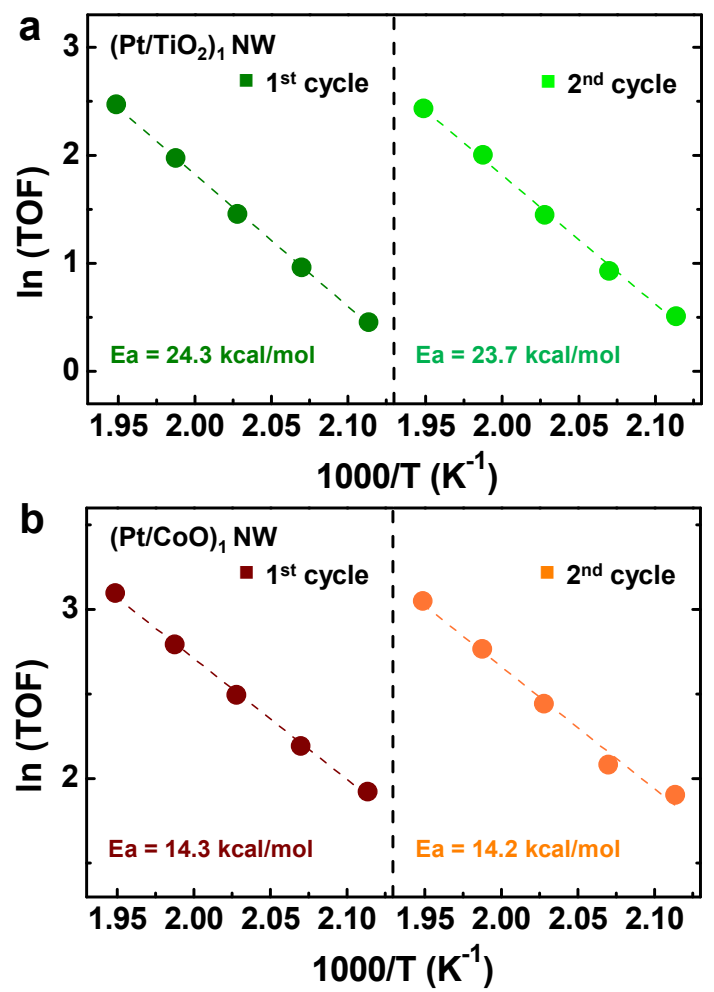

Figure S8. The Arrhenius plots for the first and second cycle of (a) $\left(\mathrm{Pt} / \mathrm{TiO}_{2}\right)_{1}$ and (b) $(\mathrm{Pt} / \mathrm{CoO})_{1}$ nanowires. 

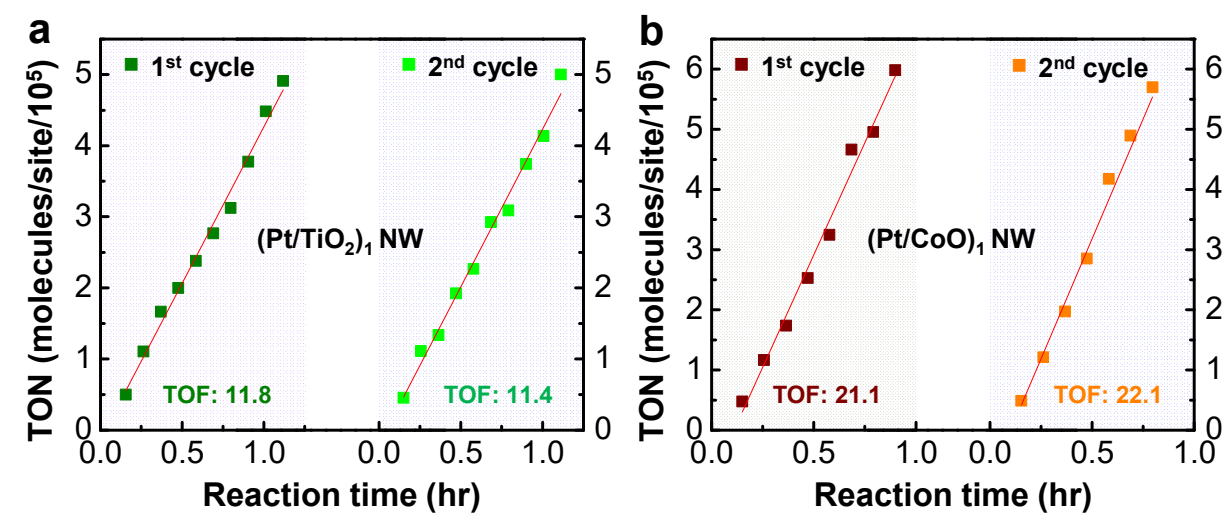

Figure S9. Turnover number at $513 \mathrm{~K}$ as a function of reaction time for the first and second cycle of (a) $\left(\mathrm{Pt} / \mathrm{TiO}_{2}\right)_{1}$ and $(\mathrm{b})(\mathrm{Pt} / \mathrm{CoO})_{1}$ nanowires. 

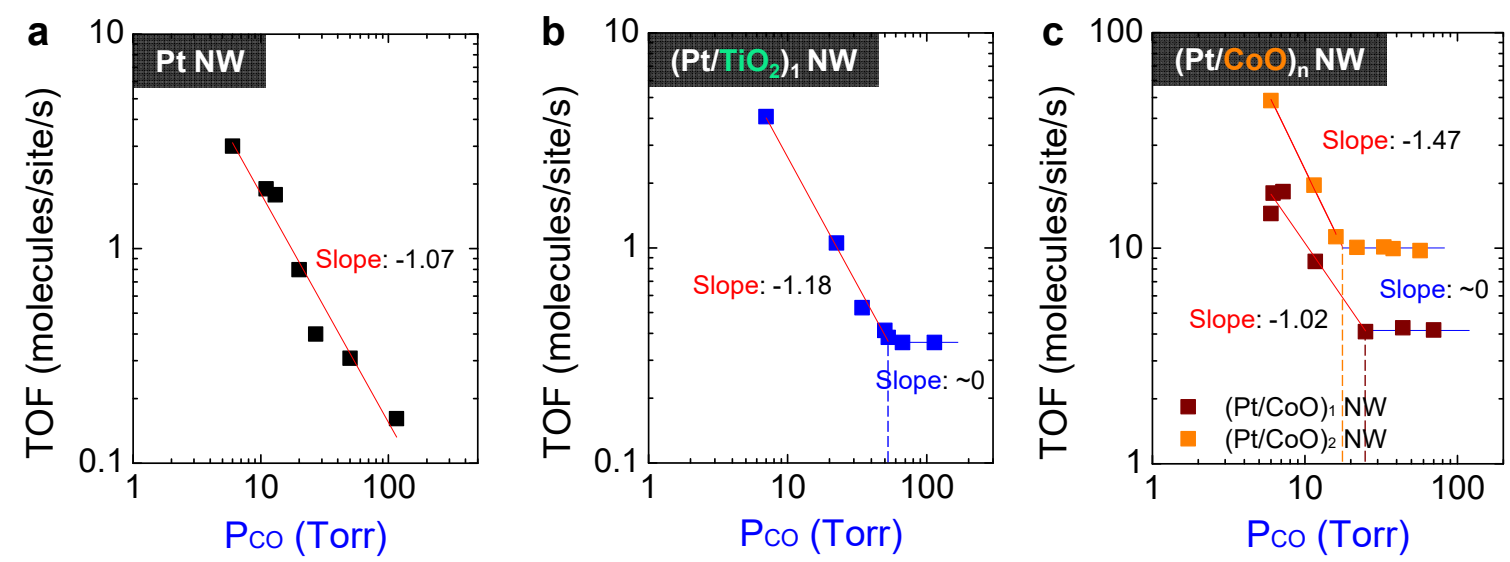

Figure S10. The kinetic study (i.e., CO dependence on the catalytic activity) of (a) Pt nanowire, (b) $\left(\mathrm{Pt} / \mathrm{TiO}_{2}\right)_{1}$, and $(\mathrm{c})(\mathrm{Pt} / \mathrm{CoO})_{1}$ and $(\mathrm{Pt} / \mathrm{CoO})_{2}$ nanowires under 10 Torr $\mathrm{O}_{2}$ at $513 \mathrm{~K}$. 


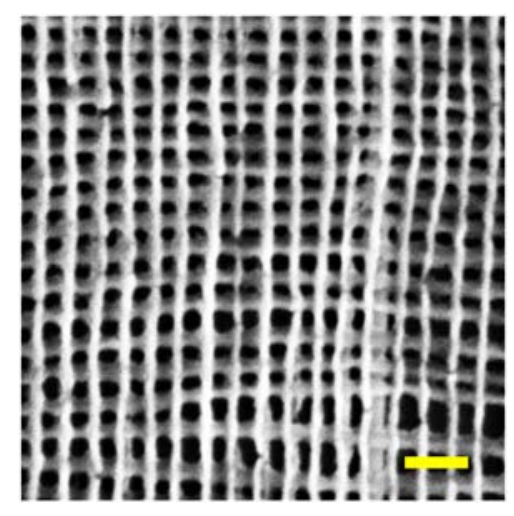

Figure S11. SEM image of the $(\mathrm{Pt} / \mathrm{CoO})_{2}$ nanowires. Scale bar is $100 \mathrm{~nm}$. 


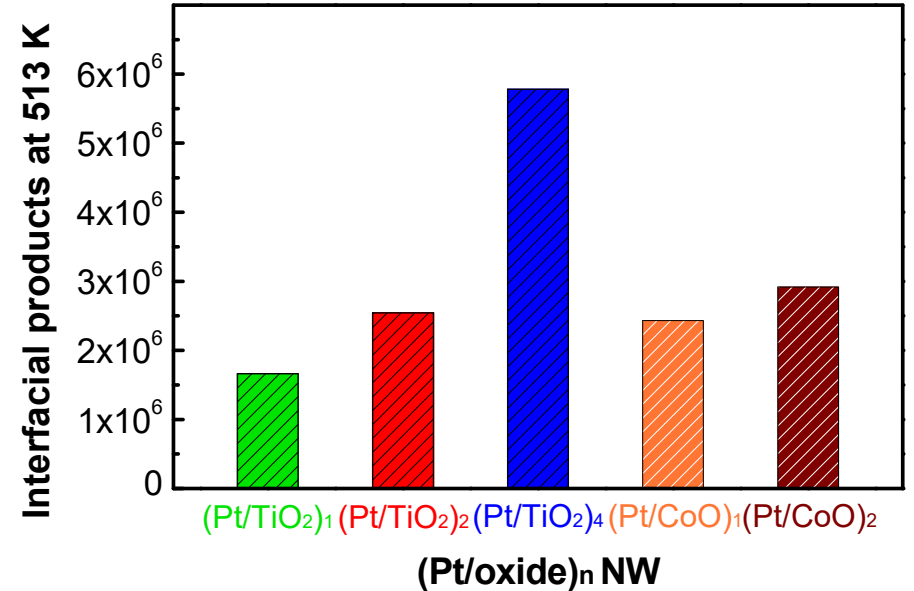

Figure S12. Interfacial products (i.e., produced $\mathrm{CO}_{2}$ molecules per hour) for the $\left(\mathrm{Pt} / \mathrm{TiO}_{2}\right)_{\mathrm{n}}$ and $(\mathrm{Pt} / \mathrm{CoO})_{\mathrm{n}} \mathrm{NW}$ complexes at $513 \mathrm{~K}$. 